\title{
Pengaruh Citra Destinasi dan Electronic Word of Mouth Terhadap Minat Berkunjung Pada Wisata Pantai Tambakrejo Blitar
}

\author{
Umma Latifa Nur Aziza ${ }^{1}$, Sugeng Purwanto ${ }^{2}$ \\ 1,2Program Studi Manajemen, Universitas Pembangunan Nasional "Veteran" Jawa Timur
}

\section{Article Info}

Article history:

Received 22 Desember 2021

Publish 04 Januari 2022

\section{Keywords:}

Tambakrejo Beach Blitar

Destination Image

Electronic Word of Mouth

Visiting Interest

\section{Info Artikel}

Article history:

Diterima 22 Desember 2021

Publis 04 Januari 2022

\begin{abstract}
Purpose of this research was to determine the effect of Destination Image and Electronic Word of Mouth on Tourist Visiting Interests on Tambakrejo Beach tourism in Blitar. This research used a quantitative approach. Nonprobability sampling method with purposive sampling technique was used for sampling with research samples obtained as many as 90 respondents. Types primary data is used in this research. Data processing is done by using Partial Least Square (PLS) analysis technique. Results of research showed that: 1) Destination Image had a significant positive effect on Tourist Visiting Interests at Tambakrejo Beach Blitar. 2) Electronik Word of Mouth has a significant positive effect on Turist Visiting Interests at Tambakrejo Beach Blitar.
\end{abstract}

This is an open access article under the Lisensi Creative Commons AtribusiBerbagiSerupa 4.0 Internasional

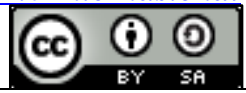

Corresponding Author:

Sugeng Purwanto

Universitas Pembangunan Nasional "Veteran" Jawa Timur

Email: sugengpurwanto.mnj@upnjatim.ac.id

\section{PENDAhUluan}

Sekarang ini kegiatan berwisata sudah menjadi bagian dari life style masyarakat yang dianggap dapat meningkatkan kualitas hidup, menghilangkan kejenuhan, relaksasi dan lainnya. Peningkatan jumlah kunjungan pariwisata didorong oleh meningkatnya minat berwisata. Tetapi, adanya pandemi Covid-19 pada tahun 2020 berdampak parah terhadap sektor pariwisata dan ekonomi kreatif di Indonesia. Menurut BPS (2021), pada tahun 2020 total kunjungan luar negeri ke Indonesia sejumlah 4,02 juta atau menurun sejumlah 75,03\% kunjungan dari tahun sebelumnya. Jamak tempat wisata domestik yang ditutup oleh pemerintah, hal ini berpengaruh pada penurunan jumlah wisatawan dan penurunan penjualan produk wisata sehingga mengakibatkan berkurangnya pendapatan pada industri pariwisata secara signifikan. 
Pantai Tambakrejo adalah satu destinasi wisata di Kabupaten Blitar, Jawa Timur yang terdampak Pandemi Covid-19. Pemerintah kabupaten Blitar pada tahun 2020 mencatat jumlah penurunan kunjungan sebesar 53.311 atau 28,2\% dibanding tahun 2019. Berikut data kunjungan wisatawan Pantai Tambak Rejo selama 5 tahun terakhir.

Tabel 1. Jumlah Kunjungan Wisatawan

\begin{tabular}{|c|c|}
\hline Tahun & Pengunjung Pantai Tambak Rejo \\
\hline $\mathbf{2 0 1 6}$ & 127.602 kunjungan \\
\hline $\mathbf{2 0 1 7}$ & 116.256 kunjungan \\
\hline $\mathbf{2 0 1 8}$ & 161.028 kunjungan \\
\hline $\mathbf{2 0 1 9}$ & 189.010 kunjungan \\
\hline $\mathbf{2 0 2 0}$ & 135.699 kunjungan \\
\hline
\end{tabular}

Sumber : Dinas Pariwisata Kebudayaan Pemuda Dan Olahraga, 2021

Program pemulihan pariwisata pasca pandemi Covid-19 tentunya membutuhkan kerjasama, sinergi, serta inovasi dengan seluruh pihak yang terkait. Keamanan dan kenyamanan dalam berwisata di era pandemi sangatlah penting. Rasa aman dan nyaman dalam berwisata dipengaruhi oleh persepsi wisatawan. Sehingga penting untuk menciptakan persepsi yang baik dimata wisatawan tentang destinasi wisata.

Menurut Hidayah (2019), citra satu tempat wisata yang dipersepsikan oleh pengunjung sebagai destinasi yang menarik dapat memengaruhi individu dalam membuat keputusan untuk mengunjungi destinasi tersebut. Citra destinasi merupakan bagian dari ekspresi dari semua pengetahuan mengenai objek, prasangka, imajinasi, dan pikiran, emosional seseorang terhadap suatu destinasi wisata (Lopes \& Sergio, 2011). Penyampaian citra destinasi harus didukung dengan strategi pemasaran yang tepat. Salah satu langkah yang dapat digunakan dalam pemulihan pariwisata yaitu dengan strategi promosi digital.

Baru-baru ini peran teknologi digital dengan berbagai media semakin meningkat, penyebaran informasi melalui media digital dapat memengaruhi minat dan keputusan berkunjung, yang mana banyak orang dapat mengunggah berbagai ulasan. Electronic word of moth merupakan ulasan berupa penilaian positif atau negatif yang diberikan oleh khalayak ramai melalui media sosial internet, hal ini bisa dikatakan bentuk dari komunikasi pemasaran yang berbasis online.

Berdasarkan uraian diatas, dengan fenomena penurunan kunjungan wisatawan maka tujuan riset ini adalah untuk mengetahui pengaruh Citra Destinasi dan Electronik Word of Mouth terhadap Minat Berkunjung wisatawan pada wisata Pantai Tambakrejo Blitar.

\section{TINJAUAN PUSTAKA}

\subsection{Citra Destinasi}

Citra destinasi yaitu persepsi individu dalam memandang tempat wisata yang berhubungan dengan destinasi maupun penyediaan fasilitas satu wisata dari fungsinya untuk memenuhi needs and wants pengunjung (Zhang et al., 2017). Citra destinasi sebagai keyakinan dan persepsi sesorang terhadap karakteristik destinsai wisata yang dibentuk oleh informasi promosi dan pengalaman di masa lalu. Lopes \& Sergio (2011), mengatakan bahwa terdapat 2 dimensi yang digunakan untuk menilai citra destinasi, yaitu :

a. Cognitive destination image, citra yang dibangun oleh konsumen berdasarkan penilaian secara rasional terhadap atraksi wisata, fasilitas dasar, aksesbilitas dan lingkungan alam suatu destinasi. 
b. Affective destination image, citra yang dibangun oleh konsumen berdasarkan penilaian secara emosional terhadap suatu yang menyenangkan, kondisi aman dan kelayakan untuk dikunjungi suatu destinasi.

\subsection{Electronic Word of Mouth}

Electronic Word of Mouth merupakan pemberian ulasan berupa testimoni dan pernyataaan postif atau negatif dari konsumen pada suatu jasa atau produk. Electronic Word of Mouth sebagai media komunikasi online untuk saling bertukar pengetahuan terkait sebuah jasa atau produk yang sudah digunakan oleh sesama konsumen yang tidak saling bertatap muka sebelumnya. Menurut Jeong \& Jang (2011), terdapat 3 indikator yang digunakan untuk menilai Electronic Word of Moth, diantaranya sebagai berikut:

a. Concern for others (kepedulian terhadap orang lain), sikap peduli konsumen kepada pihak lain untuk merekomendasikan ataupun mencegah dalam membeli produk atau jasa tetentu.

b. Expressing positive feelings, ekspresi perasaan positif yang dimotivasi oleh pengalaman konsumen dari memakai suatu produk atau jasa tertentu.

c. Helping the company, sikap tulus konsumen untuk membantu perusahaan.

\subsection{Minat Berkunjung}

Minat berkunjung dapat didefiniskan sebagai minat beli. Minat merupakan dorongan kuat untuk melakukan suatu tindakan yang muncul dari dalam individu dan dipengaruhi adanya perasaan positif sesorang dalam memandang produk atau jasa. Minat berkunjung adalah keinginan dari dalam diri seseorang untuk melakukan kunjungan di satu tempat atau daerah tertentu yang mempunyai daya tarik. Arumni (2013), menyatakan bahwa terdapat 4 indikator yang digunakan untuk menilai minat berkunjung, diantaranya sebagai berikut:

a. Minat preferensial, kedadaan yang menggambarkan seorang konsumen tertarik pada suatu jasa atau produk.

b. Minat eksploratif, aktivitas pra pembeliaan seorang konsumen untuk mencari informasi terhadap suatu jasa atau produk.

c. Minat transaksional, kemauan seorang konsumen untuk membeli suatu jasa atau produk.

d. Minat referensional, kesediaan seorang konsumen untuk merekomendasikan suatu jasa atau produk kepada pihak lain.

\subsection{Pengaruh Citra Destinasi Terhadap Minat Berkunjung}

Citra destinasi merupakan salah satu faktor penting dalam memengaruhi seseorang untuk berkunjung ke suatu destinasi wisata. Menurut Utama (2017), citra suatu destinasi mampu mendorong dan menggerakkan wisatawan dalam memilih tempat wisata. Citra sebuah destinasi yang terbukti baik dapat memperkuat keinginan calon pengunjung untuk datang melakukan kunjungan wisata ke tempat tersebut (Lin et al., 2007). Merujuk kepada Anggraeni et al. (2019) \& Mahgfiroh (2017), dari risetnya membuktikan bahwa citra destinasi memiliki pengaruh signifikan positif terhadap minat berkunjung. Sehingga berikut ini hipotesis yang diajukan:

H1: Citra Destinasi berpengaruh signifikan positif terhadap Minat Berkunjung pada Wisata Pantai Tambakrejo Blitar.

\subsection{Pengaruh Electronic Word of Mouth Terhadap Minat Berkunjung}

Electronic word of mouth merupakan bagian yang sangat memengaruhi konsumen atau wisatawan dalam membuat pilihan destinsasi favorit, karena calon wisatawan mempercayai electronic word of mouth sebagai sebuah berita yang terbaru dan lebih dapat diandalkan (Abubakar \& Ilkan, 2016). Menurut Sari \& Pangestuti (2018), electronic word of mouth mampu membantu untuk memengaruhi minat berkunjung dan dalam pengambilan keputusan berkunjung. Merujuk kepada Anggraeni et al. (2019) \& Mahgfiroh (2017), dari risetnya membuktikan bahwa citra destinasi memiliki pengaruh signifikan positif terhadap minat berkunjung. Sehingga berikut ini hipotesis yang diajukan: 
H2: Electronic Word of Mouth berpengaruh signifikan positif terhadap Minat Berkunjung pada Wisata Pantai Tambakrejo Blitar.

\subsection{Kerangka Konseptual}

Berdasarakan hipotesis yang telah diajukan, berikut kerangka konseptual dalam riset ini.

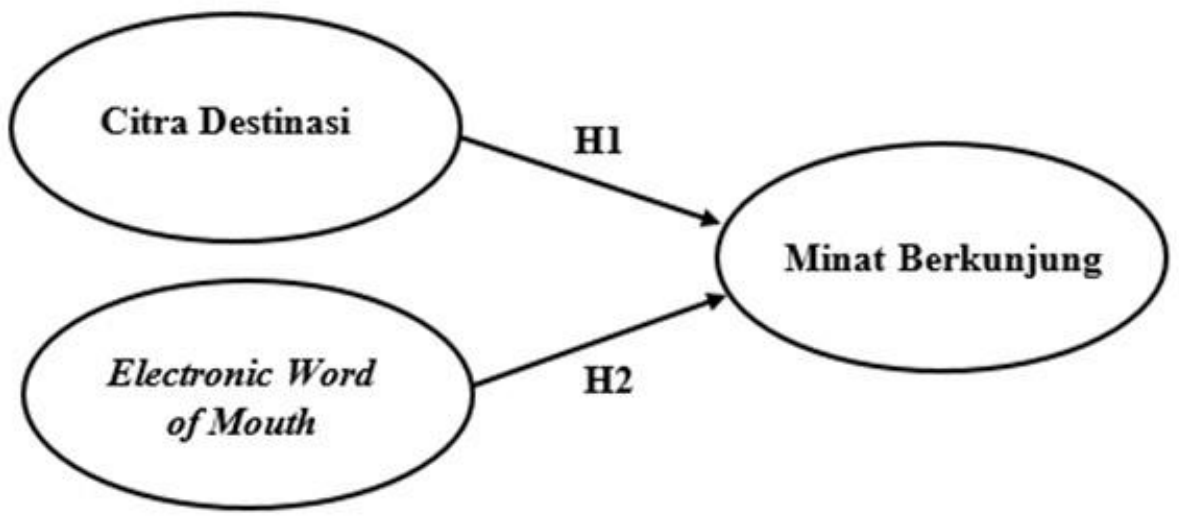

Gambar 1. Kerangka Konseptual

\section{METODE PENELITIAN}

\subsection{Jenis Penelitian}

Jenis riset ini menggunakan pendekatan kuantitatif dengan variabel Citra Destinasi, variabel Electronic Word of Mouth menjadi variable independen (X) dan variable Minat Berkunjung sebagai variable dependen (Y).

\subsection{Operasionalisasi Variabel}

Operasionalisasi variabel digunakan guna menentukan definisi operasional variabel dan indikator dari variable dalam riset.

a. Citra Destinasi (X1), citra destinasi yakni persepsi yang ada diingatan pengunjung terhadap destinasi wisata yang dibentuk dari informasi dan pengalaman di masa lalu. Indikator pengukuran variabel Citra Destinasi dari riset ini mengacu pada Lopes et al. (2011), yaitu:

(X1.1) Atraksi wisata

(X1.2) Fasilitas dasar pada destinasi wisata

(X1.3) Aksesbilitas pada destinasi wisata

(X1.4) Lingkungan alam pada destinasi wisata

(X1.5) Suatu yang menyenangkan pada destinasi wisata

(X1.6) Kondisi aman pada destinasi wisata

(X1.7) Kelayakan destinasi wisata untuk dikunjungi

b. Electronic Word of Mouth (X2), electronic word of mouth yakni ulasan negatif atau positif yang diberikan pengunjung terhadap suatu objek yang diunggah melalui media digital atau internet. Indikator pengukuran variabel Electronic Word of Mouth dari riset ini mengacu pada Jeong \& Jang (2011), yaitu:

(X2.1) Concern for other

(X2.2) Expressing positive feeling

(X2.3) Helping the company

c. Minat Berkunjung (Y1), minat berkunjung merupakan ketertarikan seseorang untuk berkunjung ke suatu tempat destinasi wisata. Indikator pengukuran variabel Minat Berkunjung dari riset ini mengacu pada Arumni (2013), yaitu:

(Y1.1) Minat preferensial

(Y1.2) Minat eksploratif 
(Y1.3) Minat transaksional

(Y1.4) Minat referensional

\subsection{Populasi dan Sampel}

Riset ini menggunakan populasi wisatawan pengguna aktif social media atau internet yang mengetahui wisata pantai Tambakrejo Blitar baik yang sudah melakukan kunjungan ataupun belum pernah melakukan kunjungan. Pengambilan sampel menggunakan nonprobability sampling method dengan purposive sampling technique. Karakter sampel yang dibutuhkan adalah: 1) Usia minimal 17 tahun. 2) Mengetahui informasi atau rekomendasi mengenai destinasi wisata Pantai Tambakrejo Blitar melalui social media atau internet. Adapun sebanyak sampel yang diperoleh sejumlah 90 responden.

\subsection{Jenis dan Sumber Data}

Riset ini menggunakan jenis primary data yang didapat dari menyebarkan kuesioner online kepada sampel riset. Adapun skala pengukuran dari instrumen riset ini menggunakan skala likert. Data yang sudah didapat dianalisis menggunakan teknik analisis Partial Least Square (PLS).

\section{HASIL PENELITIAN DAN PEMBAHASAN}

\subsection{Evaluasi Model Pengukuran}

Terlihat pada tabel 2 seluruh indikator dari variabel independen Citra Destinasi (X1), Electronik Word of Mouth (X2) dan variable dependen Minat Berkunjung (Y1) mempunyai nilai factor loading diatas 0,50. Hal ini membuktikan bahwa seluruh variabel riset ini validitasnya baik atau syarat convergen terpenuhi.

Tabel 2. Factor Loading

\begin{tabular}{|c|c|}
\hline & Factor Loading \\
\hline X1.1 <- Citra Destinasi (X1) & 0,737024 \\
\hline X1.2 <- Citra Destinasi (X1) & 0,749024 \\
\hline X1.3 <- Citra Destinasi (X1) & 0,691511 \\
\hline X1.4 <- Citra Destinasi (X1) & 0,784108 \\
\hline X1.5 <- Citra Destinasi (X1) & 0,711689 \\
\hline X1.6 <- Citra Destinasi (X1) & 0,740960 \\
\hline X1.7 <- Citra Destinasi (X1) & 0,750152 \\
\hline X2.1 <- Electronic Word of Mouth (X2) & 0,880307 \\
\hline X2.2 <- Electronic Word of Mouth (X2) & 0,750892 \\
\hline X2.3 <- Electronic Word of Mouth (X2) & 0,836660 \\
\hline Y1.1 <- Minat Berkunjung (Y1) & 0,814433 \\
\hline Y1.2 <- Minat Berkunjung (Y1) & 0,780290 \\
\hline Y1.3 <- Minat Berkunjung (Y1) & 0,804671 \\
\hline Y1.4 <- Minat Berkunjung (Y1) & 0,865551 \\
\hline
\end{tabular}

Sumber: Data Primer diolah

Terlihat pada tabel 3 seluruh indikator dari variabel independen Citra Destinasi (X1), Electronik Word of Mouth (X2) dan variable dependen Minat Berkunjung (Y1) mempunyai nilai cross loading diatas dari nilai indikator variabel lain. Hal ini membuktikan bahwa seluruh variabel riset ini validitasnya baik atau syarat discriminant terpenuhi. 
Tabel 3. Cross Loading

\begin{tabular}{|c|c|c|c|}
\hline Indikator & $\begin{array}{c}\text { Citra Destinasi } \\
\text { (X1) }\end{array}$ & $\begin{array}{c}\text { Electronic Word } \\
\text { of Mouth } \mathbf{( X 2 )}\end{array}$ & $\begin{array}{c}\text { Minat } \\
\text { Berkunjung (Y1) }\end{array}$ \\
\hline X1.1 & 0,737024 & 0,638246 & 0,593213 \\
\hline $\mathbf{X 1 . 2}$ & 0,749024 & 0,600777 & 0,663869 \\
\hline $\mathbf{X 1 . 3}$ & 0,691511 & 0,592452 & 0,553806 \\
\hline $\mathbf{X 1 . 4}$ & 0,784108 & 0,577720 & 0,630071 \\
\hline $\mathbf{X 1 . 5}$ & 0,711689 & 0,534760 & 0,535631 \\
\hline $\mathbf{X 1 . 6}$ & 0,740960 & 0,523725 & 0,543598 \\
\hline $\mathbf{X 1 . 7}$ & 0,750152 & 0,573506 & 0,658976 \\
\hline $\mathbf{X 2 . 1}$ & 0,752739 & 0,880307 & 0,693152 \\
\hline $\mathbf{X 2 . 2}$ & 0,488260 & 0,750892 & 0,511747 \\
\hline $\mathbf{X 2 . 3}$ & 0,665307 & 0,836660 & 0,655242 \\
\hline Y1.1 & 0,729905 & 0,704872 & 0,814433 \\
\hline Y1.2 & 0,534498 & 0,544132 & 0,780290 \\
\hline Y1.3 & 0,640235 & 0,511461 & 0,804671 \\
\hline Y1.4 & 0,723127 & 0,689890 & 0,865551 \\
\hline
\end{tabular}

Sumber: Data Primer diolah

Terlihat pada tabel 4 hasil pengujian AVE variebel Citra Destinasi (X1) diperoleh sejumlah 0,545072, variable Electronic Word of Mouth (X2) sejumlah 0,679593 dan variable Minat Berkunjung (Y) sejumlah 0,667207. Hal ini membuktikan bahwa seluruh variabel riset ini validitasnya baik karena didapatkan nilai AVE diatas 0,50.

Tabel 4. Average Variance Extracted (AVE)

\begin{tabular}{|c|c|}
\hline Citra Destinasi (X1) & 0,545072 \\
\hline Electronic Word of Mouth (X2) & 0,679593 \\
\hline Minat Berkunjung (Y1) & 0,667207 \\
\hline
\end{tabular}

Sumber: Data Primer diolah

Terlihat pada tabel 5 hasil pengujian composite reliability variebel Citra Destinasi (X1) diperoleh sejumlah 0,893339, variable Electronic Word of Mouth (X2) sejumlah 0,863687 dan variable Minat Berkunjung (Y1) sejumlah 0,888986. Hal ini membuktikan bahwa seluruh variabel riset ini reliabel karena didapatkan nilai reliability diatas 0,70 .

Tabel 5. Composite Reliability

\begin{tabular}{|c|c|}
\hline & Composite Reliability \\
\hline Citra Destinasi (X1) & 0,893339 \\
\hline Electronic Word of Mouth (X2) & 0,863687 \\
\hline Minat Berkunjung (Y1) & 0,888986 \\
\hline
\end{tabular}

Sumber: Data Primer diolah

\subsection{Evaluasi Model Struktural}

Tabel 6 menunjukkan nilai $\mathrm{R}^{2}=0,700465$. Hal ini dapat dijelaskan bahwa variabel Minat Berkunjung (Y1) yang dipengaruhi oleh variable independen Citra Destinasi (X1) dan 2082 | Pengaruh Citra Destinasi dan Electronic Word of Mouth Terhadap Minat Berkunjung 
Electronic Word of Mouth (X2) memiliki varian sejumlah 70,04\%. Sisannya 29,96\% dijelaskan oleh variable lain diluar riset.

Tabel 6. R-Square

\begin{tabular}{|c|c|}
\hline & R Square \\
\hline Citra Destinasi (X1) & \\
\hline Electronic Word of Mouth (X2) & \\
\hline Minat Berkunjung (Y1) & 0,700465 \\
\hline
\end{tabular}

Sumber: Data Primer diolah

\subsection{Pengujian Hipotesis}

Tabel 7. Pengujian Hipotesis

\begin{tabular}{|c|c|c|}
\hline & Path Coefficients (O) & $\begin{array}{c}\text { T Statistics } \\
(\mid \mathbf{O} / \text { TERR })\end{array}$ \\
\hline $\begin{array}{c}\text { Citra Destinasi (X1) -> Minat } \\
\text { Berkunjung (Y1) }\end{array}$ & 0,564935 & 7,279470 \\
\hline $\begin{array}{c}\text { Electronic Word of Mouth (X2) } \\
\text { (X2) -> Minat Berkunjung (Y1) }\end{array}$ & 0,317301 & 3,383360 \\
\hline
\end{tabular}

Sumber: Data Primer diolah

Tabel 7 menunjukkan hasil pengujian hipotesis yang menyatakan bahwa:

a. Citra Destinasi (X1) berpengaruh positif terhadap Minat Berkunjung (Y1) dapat diterima, syarat signifikansi terpenuhi karena diperoleh nilai path coefficients diatas 0,05 dan nilai $T$-statistic lebih besar dari 1,96.

b. Electronic Word of Mouth (X2) berpengaruh positif terhadap Minat Berkunjung (Y1) dapat diterima, syarat signifikansi terpenuhi karena diperoleh nilai path coefficients diatas 0,05 dan nilai $T$-statistic lebih besar dari 1,96.

\subsection{Pengaruh Citra Destinasi (X1) Terhadap Minat Berkunjung (Y1)}

Berdasarkan hasil riset yang telah dilakukan, variabel Citra Destinasi berpengaruh signifikan positif terhadap Minat Berkunjung wisatawan ke pantai Tambakrejo Blitar. Hasil riset ini didukung oleh riset Anggraeni et al. (2019) \& Mahgfiroh (2017) yang membuktikan terdapat pengaruh antara citra destinasi dan minat berkunjung secara positif. Artinya, semakin baik citra destinsi pada satu tempat wisata hal tersebut mampu menarik minat wisatawan untuk berkunjung. Citra satu tempat wisata yang dipersepsikan oleh sesorang akan mampu memotivasinya dalam menentukkan pilihan untuk melakukan kunjungan wisata ke destinasi tersebut (Hidayah, 2019). Adanya citra destinasi yang positif dapat memengaruhi wisatawan dalam proses memilih dan mengevaluasi untuk menentukan minat berkunjung di masa mendatang. Oleh karena itu, dapat diambil kesimpulan bahwa citra destinasi adalah aspek penting dalam mendorong terbentuknya minat berkunjung wisatawan ke pantai Tambakrejo Blitar.

\subsection{Pengaruh Electronic Word of Mouth (X2) Terhadap Minat Berkunjung (Y1)}

Berdasarkan hasil riset yang telah dilakukan, variabel Electronic Word of Mouth berpengaruh signifikan positif terhadap Minat Berkunjung wisatawan ke pantai Tambakrejo Blitar. Hasil riset ini didukung oleh riset Anggraeni et al. (2019) \& Mahgfiroh (2017) yang membuktikan terdapat pengaruh antara electronic word of mouth dan minat berkunjung secara positif. Artinya, electronic word of mouth yang baik pada satu tempat wisata dapat menarik minat wisatawan untuk melakukan kunjungan. Ulasan positif di social media atau internet yang 
berhubungan dengan Wisata Pantai Tambakrejo Blitar mampu mendorong minat wisatawan untuk berkunjung. Menurut Abubakar \& Ilkan (2016), calon wisatawan lebih mempercayai informasi dari electronic word of mouth yang sifatnya lebih terupdate dibandingkan informasi promosi yang disediakan oleh perusahaan. Oleh karena itu, dapat diambil kesimpulan bahwa electronik word of mouth merupakan aspek penting untuk meningkatkan minat berkunjung wisatawan ke pantai Tambakrejo Blitar.

\section{KESIMPULAN}

Kesimpulan dari artikel ini sebagai berikut:

a. Citra Destinasi (X1) memiliki kontribusi terhadap Minat Berkunjung (Y1). Hal ini dapat diartikan bahwa citra destinasi yang baik mampu mendorong wisatawan untuk berkunjung ke pantai Tambakrejo Blitar.

b. Electronic Word of Mouth (X1) memiliki kontribusi terhadap Minat Berkunjung (Y1). Hal ini dapat diartikan bahwa electronic word of mouth yang baik mampu mendorong wisatawan untuk berkunjung ke pantai Tambakrejo Blitar.

Adapun saran yang diberikan diharapkan kepada pengelola wisata Pantai Tambakrejo Blitar untuk terus meningkatkan citra destinasi. Pengelola dirasa perlu untuk menjaga kelestarian lingkungan alam di area wisata Pantai Tambakrejo Blitar agar destinasi wisata tetap dipandang baik oleh pengunjung. Selain itu, diharapkan pula kepada pengelola wisata Pantai Tambakrejo Blitar untuk mengaplikasikan strategi electronic word of mouth dengan memanfaatkan berbagai konten digital yang dapat menarik perhatian calon pengunjung sehingga memengaruhi adanya keinginan untuk berwisata di Pantai Pantai Tambakrejo Blitar.

\section{DAFTAR PUSTAKA}

Abubakar, A. M. \& Ilkan, M. (2016). Impact of Online WOM on Destination Trust and Intention to Travel. Journal of Destination Marketing and Management, 5(3), 192-201.

Anggraeni, D., Supriyanto, A. \& Fianto A. Y. S. (2019). Pengaruh City Branding, Motivasi Wisata, E-WOM, Citra Destinasi dan Daya Tarik Terhadap Minat Berkunjung Wisatawan di Kabupaten Banyuwangi. Jurnal Ilmu Manajemen Indonesia, 1(4), 1-13.

Arumni, K. V. (2013). Pengaruh Gaya Hidup Brand Minded dan Peran Kelompok Acuan Terhadap Minat Beli Produk Smartphone Samsung Berbasis Android. Skripsi. Universitas Sanata Dharma, Yogyakarta.

BPS (2021). Jumlah Kunjungan Wisman ke Indonesia Bulan Desember 2020 Mencapai 164,09 Ribu Kunjungan: Badan Pusat Statistik

Hidayah, N. (2019). Pemasaran Destinasi Pariwisata. Bandung: Penerbit Alfabeta.

Jeong, E. \& Jang, S. C. (2011). Restaurant Experience Triggering Positive Electronic Word of Mouth (EWOM) Motivations. International Journal of Hospitality Management, 30(2), 356-366.

Lin, J. W., Li, J. F. \& Yang, J. S. (2006). The Effect of Audit Committee Performance on Earnings Quality. Managerial Auditing Journal, 21(9), 921-933.

Lopes \& Sergio, D. F. (2011). Destination Image: Origins Development and Implications. Politechnic Institute of Cavado and Ave Portugal.

Sari, F. \& Pangestuti, E. (2018). Pengaruh Electronic Word Of Mouth (E-Wom) Terhadap Minat Berkunjung dan Keputusan Berkunjung. Jurnal Administrasi Bisnis, 54(1), 189-196.

Utama, I. B. R. U. (2017). Pemasaran Pariwisata. Yogyakarta: Penerbit ANDI.

Zhang, H., Gursoy, D., \& Xu, H. (2017). The Effects of Associative Slogans on Tourists'Attitudes and Travel Intention. Journal of Travel Research, 56(2), 206-220. 